\title{
Establishing ecological and social continuities: new challenges to optimize urban watershed management
}

\author{
V. MITROI, A. DE CONINCK, B. VINÇON-LEITE \& J-F. DEROUBAIX \\ LEESU - Laboratoire Eau Environnement et Systèmes Urbains, Ecole des Ponts ParisTech, France \\ veronica.mitroi@leesu.enpc.fr
}

\begin{abstract}
The (re)construction of the ecological continuity is stated as one of the main objectives of the European Water Framework Directive for watershed management in Europe. Analysing the social, political, technical and scientific processes characterising the implementation of different projects of ecological continuity in two adjacent peri-urban territories in Ile-de-France, we observed science-driven approaches disregarding the social contexts. We show that, in urbanized areas, ecological continuity requires not only important technical and ecological expertise, but also social and political participation to the definition of a common vision and action plan. Being a challenge for both, technical water management institutions and "classical" ecological policies, we propose some social science contributions to deal with ecological unpredictability and reconsider stakeholder resistance to this kind of project.
\end{abstract}

Key words ecological continuity; urban watershed management; small rivers; urban ponds; Green and Blue Corridors; Ile-de-France

\section{INTRODUCTION}

Ecological continuity, one of the core objectives of the European Water Framework Directive (WFD), appears as a new challenge for the management of urbanised watersheds in Europe. In the Ile-de-France region, according to the WFD, the main concern is for watercourses, but it also has an impact on lake and pond management. In the case of rivers, the ecological continuity mainly involves removing sluice gates, connecting rivers and wetlands and re-naturalizing the riverbanks. Hydraulic continuity is considered as a guarantee for a better circulation of the aquatic fauna, a better circulation of the sediments, and finally an improvement of the water quality. Urban lakes and ponds are less concerned by the WFD water quality requirements. Ecological continuity is thus an opportunity for these water bodies to be (re)connected to watersheds and to reach the same quality norms. In practice, ecological continuity refers to various applications and local policies, sometimes conflicting. In different contexts, neither the definition of water bodies, nor the ecological objectives, or the measures promoted are the same. When this concept is implemented on a specific river or lake, various oppositions can occur from water managers, elected representatives, managers of human activities, ecological organisations, etc. These projects try to conciliate various goals: biodiversity improvement and various wetland functions, flood-risk management, urban nature for social purpose, etc. (Morandi and Piégay 2011). A compromise must be found between ecology, social and economic needs and technical constraints. In order to avoid local resistance and weak effectiveness ("connectivity only on paper") of the programs, ecological restoration should address social issues and be understood by all stakeholders. In this paper we analyse the way ecological continuity affects small urban water bodies' management. What are the ecological objects connected to one another? Which binds and whose participation are required? How are ecological objectives linked to socio-political ones and to other water policies' goals? Does ecological continuity lead to a real change of the management practices or is it just another word to name the former water management practices? We address these questions by comparing different projects of ecological continuity concerning surface water (lakes and ponds) on two adjacent territories in the Ile-deFrance peri-urban area.

\section{ECOLOGICAL CONTINUITIES - A NEW FRAMEWORK FOR THE MANAGEMENT OF WATER BODIES IN THE ILE-DE-FRANCE REGION}

\section{The patchwork of water bodies in Ile-de-France}

The Île-de-France region is situated between large floodplains created by the meanders of the River Seine and its major tributaries, such as the Marne and the Oise rivers. These water streams played 
an important role and were heavily transformed with the socio-economic development and urbanisation of the region. Île-de-France is the fourth densest region in the European Union (11.7 million inhabitants, and 980 inhabitants $/ \mathrm{km}^{2}$ ) and the most populated region of France with $19 \%$ of the population on $2 \%$ of the national territory (Marchand 2007). With the urbanisation of the peripheral areas and the construction of the "New Cities" (les Villes Nouvelles), Île-de-France roughly lost, within the last 50 years, $1000 \mathrm{~km}^{2}$ of rural and natural habitats. In spite of this massive urbanisation, Île-de-France is essentially a rural region; half of its surface is used for agriculture (Bertaud et al. 2004). The extension of residential suburbs and the creation of a complex network of infrastructures ( $800 \mathrm{~km}$ of motorways, $3900 \mathrm{~km}$ of railways, etc.) changed not only its landscape, but also the hydro-morphology of the surface water. In the most urbanised areas, important parts of the rivers were covered, being completely transformed into stormwater or wastewater infrastructures. Still, the aquatic ecosystems are more important than what is generally supposed in the complex mixture of urban, peri-urban and rural areas characterizing Île-de-France. The region presents no less then $1700 \mathrm{~km}$ of rivers and 990 lakes, reservoirs and ponds (Catherine et al. 2008). New man-made reservoirs and canals have been added to the existing ones, contributing to a patchwork of water bodies more or less connected to the natural environment. Today they accomplish multiple services: regulation services (water purification, flood control, water supply, biodiversity conservation, etc.), cultural services (recreational activities, fishing, tourism, education) and ecological services (Natura 2000, natural protected areas, etc). The ecological continuity is considered today as one of the main management practices to assure the co-existence of these different functions and to reconsider their ecological and social values.

\section{The issue of ecological continuity in the French context - competing knowledge and definitions of ecological continuity}

The concept of ecological continuity is nowadays enacted in water planning procedures, namely the SAGE procedure (Schémas d'Aménagement et de Gestion des Eaux), but also in some urban planning procedure, such as the TVB (Trames Verte et Bleue - Green and Blue Corridors), or other environmental protection policies (such as: ecological corridors, protected areas networks, etc.). These different ways of defining ecological continuity involve different issues, actors, knowledge and territories. In France, since the 1992 Water Act, SAGEs are the main water governance procedures at the watershed level. Their implementation implies the creation of a Local Water Committee (CLE - Commission Locale de l'Eau), involving local elected representatives of the concerned localities (half of the members), territorial representatives of the central State administrations (a quarter) and members of local associations: fishermen, ecologists, aquatic sports, farmers and industrial entrepreneurs (a quarter). The CLE can bring together 30 to 50 members, to decide the objectives and measures in order to improve water management. SAGEs strictly deal with water management issues, and therefore mostly deal with "longitudinal continuity" of rivers, and the connections between surface water and groundwater. This procedure considers the water resource as a whole, at the watershed scale. Urban master plans must be amended in order to be coherent with SAGEs, but the link between urban planning and water management is far from being acted. The TVB is an urban planning tool. The TVB originates in the "Grenelle Environmental Forum" (Loi Grenelle 2009), stipulating the obligation for local communities to "maintain and reconstitute a network of corridors so that animal and plant species, can communicate, circulate, find food, reproduce and rest". This definition stresses the ecological importance of water infrastructures for urban biodiversity; they are considered as "biodiversity reservoirs". This urban planning policy establishes "lateral continuity" both between different water bodies and between water bodies and "green" elements. Ecological continuity and restoration, particularly in urban contexts, is a complex collective decision-making process that involves a diversity of stakeholders and experts, each with their own perceptions and preferences about ecological or urban landscapes. The European WFD specifies the importance of the stakeholders' participation to the ecological continuity and restoration programs but leaves to each management structure the possibility to define the modalities and the intensity of this participation (Allain 2001). In this article we examine how 
different projects of ecological continuity were implemented in Ile-de-France. The two case studies concern a lake and a river situated on adjacent territories, represented by two different SAGE. The SAGE of Bièvre (including the Saint-Quentin Lake) and the SAGE of Orge-Yvette (representing the Orge River) are very similar territories, confronted with similar problems of water quality and highly modified watersheds. By comparing the ecological continuities implemented on these territories, we show the diversity of practices and definition of ecological continuities for different kind of water bodies. Our insights about the social issues involved by these projects are based on interviews with the main stakeholders (10-12 interviews per site) and on the participatory observation of collective meetings addressing ecological continuity projects.

\section{Saint-Quentin-En-Yvelines Periurban Lake - which ecological continuity for which lake?}

Our first case study concerns one of the biggest (200 ha) lakes of the Ile-de-France region. The lake was created at the end of the 17 th century as the downstream retention point of a complex hydraulic network, draining a plateau of 6000 ha. The network was meant to supply water for Versailles Chateau fountains. This initial function ended in 1977, but it still has a draining function for the hydraulic network. Nowadays its watershed consists of a mosaic of agricultural lands, forests, residential areas and important transport infrastructures. The construction of the "new city" of SaintQuentin-en-Yvelines in the 1970s involved a radical change of the lake's functions and uses. It became a place dedicated to recreational activities, mainly windsurf and other nautical sports. An important Leisure Park is managing these activities and represents the main manager of the lake. Still, the lake also plays an important flood protection role, being a stormwater retention basin for the city. A treatment lagoon meant to improve the storm water quality discharged into the lake was created. The lake flows into the Bièvre River and reaches, after crossing several suburbs of Paris, the Seine River. In 1982, the hydrological management of the upstream network and of the lake was delegated to a Joint Local Authority - SMAGER (Syndicat mixte de gestion du réseau d'étangs et rigoles), bringing together representatives of all the municipalities and of the Leisure Park. Its first mission was the maintenance of the network in order to prevent floods. In 1986, an ornithological organisation (le Groupe Ornithologique de Paris - GOP) initiated a project for the settlement of a National Nature Reserve on one side of the lake ( $87 \mathrm{ha}$ ). The ecological value ( 230 birds species have been identified) was acknowledged, but the National Commission pointed out some "problems with the quantity and the quality" of the lake's water. It took 20 years for the management plan to be actually validated in 2006, but still the reserve's managers highlight the fragility of this protected area, facing increasing conflicts of use and risk of pollution. The ecological importance of the lake was strengthened in 2003 by the Natura 2000 site nomination. The ecological valuation of the lake has contributed to the improvement of its quality. Still, this strong ecological protection becomes a source of conflict, not only between different uses, but also between different management policies. The conflict of uses refers mainly to the co-existence of different needs for social, ecological and hydrological use. This conflict was partially solved by a strict spatial division between natural areas and social activities areas. The reserve was enclosed 10 years after its creation, in order to protect the site from users of the Leisure Park: "without barriers, there is no possible protection!" (Natural Reserve manager). Another answer to the conflict of use was the negotiation of a consensual water level curve in 2011 that conciliates the different water needs of the main actors: the Leisure Park, the Natural Reserve and the SMAGER. If all the actors acknowledge the ecological importance of the lake, its integration to larger management plans (such as ecological continuity) still has to be defined and negotiated. The superposition of different administrative and management units (district, city, river catchment, nature protection, water management and urban planning), has as a consequence the definition of different ecological continuity management plans. The first is the master plan for the Bievre River watershed (SAGE). In that case, the hydrological continuity requires the same quality standards for the lake and for the connected natural river. Its main objective is the reduction of the negative impact of the urban stormwater input on the lake. A second project of ecological continuity is developed by the city of Saint-Quentin as an urban planning tool (TVB). This project focuses on the landscape connection between different green and blue spots of the city. 
Finally, a third type of ecological continuity concerns directly the ecological value of the lake and is promoted as part of the Natural Protected Areas National Strategy. As the size of the existing natural reserve of Saint-Quentin-en-Yveline's lake is "critical" (not big enough to assure the protection of the aquatic ecosystem by itself), an ecological continuity project concerns the expansion of the protected area of the lake by the creation of a bigger reserve (or a network of small reserves) on the entire upstream watershed. Each of these ecological continuity projects redefines the lake's functions and quality exigencies. As no initiative is taken in order to "link" these different projects together, some competing visions between projects are emerging. From the point of view of the SAGE promoters, the biological and chemical quality of the lake is the priority. The role of the treatment lagoon, managed since its creation by the natural reserve, then becomes very important. But the natural reserve does not assume this treatment function: "The management of this lagoon is strictly done from an ecological point of view, meaning that the water level must vary according to the nesting periods. On the contrary to accomplish its water treatment function, the lagoon should be continuously provided with water. But the role of the natural reserve is not to clean the water of the city" (Natural Reserve manager).

According to the TVB ecological continuity, the lake is defined as a biodiversity reservoir, the most important natural site on the territory. Still, its physical, chemical and biological water quality are not considered as the most important issues. The urban planers try to estimate the value of the ecosystem services of the lake. The ecologists are very sceptical, considering that the TVB could be instrumentalized into greening urban policies by the Leisure Park and the urban planners, without considering a substantial protection of the environment. Finally, the ecological continuity proposed by the Nature Conservation Committee is criticized by the Joint Local Authority - SMAGER. Their main criticism is that: "Too much protection blocks the current and rapid intervention on the network, absolutely necessary for the principal flood risk mission" (SMAGER). The three projects are not conflicting so much at this stage of their implementation, because different political fields and management structures are in charge of each of them. Still, we can observe competing visions about the lake, each project articulating different actors, resources, territorial scales and different degrees of ecological protection for the lake. Actors involved do not necessarily communicate or take into account the compatibility between these parallel projects and disregard the diversifying uses and functions of the lake.

\section{The Orge River}

The second territory we would like to present in this paper is the Orge River valley. The Orge River is a $50 \mathrm{~km}$ long tributary of the Seine River, in the Paris suburbs, which runs first through agricultural land, then through urbanised areas. Its watershed covers $950 \mathrm{~km}^{2}$. The Orge has been modified by engineering in order to control water-levels and the increasing flood risk due to the soil imperviousness generated by the urbanisation in the last 30 years. There are two Joint Local Authorities in charge of the river management. We focused our study on the Joint Local Authority (Syndicat mixte de la vallée de l'Orge aval - SIVOA) managing the downstream and most urbanized part of the watershed, encompassing 37 cities with a total of 370000 inhabitants. SIVOA was created at the beginning of the 1930s and has now reached 90 technicians. Their initial goal of hydraulic management (focused on wastewater services and flood prevention) evolved to an ecological management during the 1990s (Guillerme and Viviane 1986). This ecological management consists, for instance, in removing some banks of the river made of concrete, and making flora and fauna inventories. SIVOA's programs are quite exemplary as they have always been very proactive and innovative in the management of the river (Carré et al. 2011). They try to manage together different issues: flood prevention, river pollution and also restoration of the rivers "natural" state. This restoration consists of favouring hydrological functionalities and dynamics in order to protect and enhance the natural environment. They work with hydrologists, landscapers and ecologists. From the 29 dams constructed on the downstream portion of the river, the Joint Local Authority has removed 21 of them so far. After having restored the longitudinal hydrological continuity of the river, SIVOA is now trying to better articulate the river management to the 
watershed management, in an attempt to obtain a lateral ecological continuity. It tries to integrate the river with its urban and natural environment (the hillsides and the valley). In this new ecological continuity perspective, the river would become a key element of the territory and of the identity of the valley. Therefore, the creation of Green and Blue Corridors is one of the core objectives of their current management scheme (2014-2018). This new paradigm implied a lot of communication towards the SIVOA employees, to change the way they were working. It also faces some opposition and misunderstandings from the local cities (especially those that are not directly connected to the river). The Green and Blue Corridors encourage participation in theory, but in practice it is quite rare that ecological restoration is discussed with non-experts. Up to now it is a scientific notion, and, according to the technicians, its implementation requires technical abilities or skills. Therefore it does not open the debate of the water management question. It does not help to build a new water management paradigm that could take into account different expertise and allows different uses. In the Orge River watershed, the technicians of the water SIVOA want to keep the control over the design of the ecological continuity. They claim their monopoly to define what biodiversity is, and they play a decisive role in the elaboration of the management schemes (stating the planning and the maintenance of the watercourses). This scheme has to be approved by representatives from the municipalities later. Still the local elected representatives are not involved in the elaboration process. During the interviews technicians freely express this strategy: "[sceptical] Municipalities will be convinced as soon as they see that our restoration projects do not lead to chaos, such as proliferation of invasive species, mosquitoes, drying up of the river in some parts" (SIVOA). SIVOA owns part of the Orge riverbanks. Still most of the land that could be integrated in Green and Blue corridors belongs to municipalities. Those municipalities are not necessarily experts about water management, and their perception of the ecological continuity concept is no more than a regulation trying to prevent them from urbanising their territory. The risk is that green and blue corridors may be inscribed in their urban planning master plan, but just as a recommendation. This notion may not deeply question their way of doing water management or urban planning. There is also a gap between the municipalities close to the river and rather interested in the water issues, and the others, mostly not aware. How could non-experts understand this concept of Green and Blue Corridors? How to debate about the expert knowledge? How can the expertise be accessible to non-experts, and enriched by non-experts? On this territory, we set up an experiment to open the debate of ecological restoration with non-experts. A citizen conference about green and blue infrastructures and its implementation on the Orge watershed was held at the end of 2013. A citizen conference is a participation tool inviting citizens to deliberate and formulate informed opinions about complex issues. The participants in citizen conferences are selected randomly to represent a diverse set of opinions and demographics of a region. These participants are usually ordinary citizens, not stakeholders or professional lobbyists. A panel of experts is selected to represent a broad range of expertise on the specific sector being discussed. A moderator brings his help during the deliberation part of the event. Experts expose an overview of the problem to the citizens, who then discuss and give a synthesis of their recommendation and opinion about the issue. Our experiment should lead the citizen to expose how biodiversity and nature might exist on their territory. They will give their definition and their appropriation of the Green and Blue Corridors. From a social science point of view, the idea is to compare their knowledge to the scientists' and managers' knowledge. How do they deal with the uncertainty characterising the idea of ecological continuity? What kind of dilemma do they see between biodiversity and others uses of the aquatic ecosystems? We can explore how their representation can converge or not to build a common project on this territory.

\section{CONCLUSION - HOW TO LINK ALTERNATIVE CONNECTIVITIES?}

The cross-reading of the two cases suggests that ecological continuity covers a large diversity of practices, even on very similar territories. Generally meant in an urban context as a transition from water infrastructures to "green" water infrastructures, ecological continuity requires the formulation of new goals and new content of these water infrastructures in connection with the dynamics of a given territory. Ecological continuity programs are not only a technical issue, but they are also a 
matter of political choice. On the two studied territories, we observe that there is no pre-existing consensus on the "green" or ecological functions of urban water infrastructures but competing expertise, knowledge and projects. It is difficult at this stage to generalize observations about the on-going process of ecological continuity. Different management principles must be applied on the basis of different social uses, constraints and ecological specificity of each site. But a general observation can be formulated. Despite different attempts to include different actors and knowledge to the definition of ecological continuity, as stated by the WFD, non-integrative management practices are still going on. The ecological continuity projects observed in the field do not yet directly impact the water management practices. Even if the ecological continuity supposes the replacement of existing infrastructures (e.g. sluice gates, valves, concrete riverbanks, etc.) by softer technologies and practices, we observed science-driven approaches, disregarding the practical social contexts. One of the main obstacles counteracting the implementation of the ecological continuity projects seems to be the difficulty to obtain social and political participation to the definition of a common vision and action plan on what the ecological continuity is and how to obtain it. We show that on very similar territories, and even on the same one, the definition of ecological continuity varies with the actors involved. The first case study shows that perceptions and definition of ecological continuity are different from one "promoter" to another. The weak integration of different projects leads to conflicts between actors, who are not able to define a common action plan. In the second case we have, on the contrary, one single manager (SIVOA) that monopolises the definition of ecological continuity. Rather than providing one single, ready-made solution for the ecological continuity, the managers must integrate in their plans and actions the need of the concrete appropriation of the concept by a large scale of social actors and users. Ecological continuity should go together with social connectivity. That means establishing links between actors that were not working together, changing knowledge and sharing competencies before. This social connectivity needs to be facilitated so that different expertise, interests, uses could be taken into account. Even if some territorial compromises have been reached, it is very difficult to estimate by now the concrete social and ecological benefits. Nevertheless, in the experiment we made on the Orge River, we observe that confronting the different interpretations of ecological continuity is not enough to formulate a common project on the territory. The definition of convergent social and ecological benefits is a social issue that can be addressed only with the participation of all the concerned actors. Some more social than technical solutions are still not discussed because they seem to be more complex and more conflicting. But the long-term success of the ecological continuity cannot be reached without this preliminary work of social consensus and social connectivity around the ecological continuity being implemented.

\section{REFERENCES}

Allain, S. (2001) Planification participative de bassin et gouvernement de l'eau. Geocarrefour 3, 13-19.

Bertaud, T., Delas, M. and Jalier, M. (2004) Key figures of the Île-de-France Region - 2004. Institute for Urban Planning of the Paris Île-de-France Region Report (IAURIF). doi: http://www. iaurif.org/en/doc/studies/key figures/index.htm.

Carré, C., et al. (2011) Les petites rivières urbaines d'Île-de-France. Agence de l'Eau Seine-Normandie.

Catherine, A., Troussellier, M. and Bernard, C. (2008) Design and application of a stratified sampling strategy to study the regional distribution of cyanobacteria (Île-de-France, France). Water Research 42, 4989-5001.

Guillerme, A. and Viviane, C. (1986) L'Orge et ses syndicats: approches historiques et techniques d'une rivière périurbaine, Ecole Nationale des travaux publics de l'Etat.

Marchand, O. (2007) Enquêtes annuelles de recensement de 2004-2006. Insee Report.

Morandi, B. and Piégay H. (2011) Les restaurations de rivières sur Internet: premier bilan. Natures, Sciences, Sociétés 3(19), $224-235$. 